\title{
TELESCOPING OSTEOTOMY FOR PRESSURE METATARSALGIA
}

\author{
B. HELAL, M. GREISS \\ From the London Hospital, London, the Enfield District Hospital, Winchmore Hill, \\ and the Derbyshire Royal Infirmary, Derby
}

\begin{abstract}
A review is presented of $\mathbf{5 0 8}$ feet in $\mathbf{3 1 0}$ patients after telescoping osteotomy of the lesser metatarsals for metatarsalgia. The patients were predominantly female (80\%), with a mean age of 55 years; the range of follow-up was 1 to 12 years. In $22 \%$ of the patients the metatarsalgia was associated with rheumatoid arthritis. Improvements in assessment and modifications in technique are reported and the management of complications is discussed. The results show that telescoping osteotomy for established cases of pressure metatarsalgia is a simple and reliable operation. Permanent relief of symptoms can be expected in over $80 \%$ of patients.
\end{abstract}

Pain in the region of the metatarsals and metatarsophalangeal joints is called metatarsalgia. When pain occurs on bearing weight it is termed pressure metatarsalgia. The common cause is displacement of the normal pressure-bearing pads of fat from beneath one or more of the metatarsal heads. The skin underlying the metatarsal heads thickens to form callosities which are the usual source of pain. In longstanding pressure metatarsalgia the soft tissues beneath the metatarsal heads condense and mould themselves around the metatarsal heads, to which they may become firmly attached.

DuVries (1965) stated that between $50 \%$ and $70 \%$ of adults in civilised society have or will have some foot disorder; and that $90 \%$ of these disorders affect the forefoot.

Kelikian (1965) considered that pressure metatarsalgia was the most common type of metatarsalgia as well as the most disabling problem of the forefoot; he writes "At its inception the metatarsal head's plantarwards descent is reversible. In time, it becomes rigid, and fixed plantar prominence of the middle metatarsal head occurs. The toes assume a retractable position, their joints stiffen, and plantar keratoses form under the prominent heads."

When static disorders of the forefoot become established they can only be corrected surgically. In 1967 an osteotomy performed in the distal third of the shaft of the middle three metatarsals was devised by one of us (BH). Early weight-bearing was an important feature and promoted dorsal displacement, so levelling the tread. The early cases were reported in this journal (Helal 1975).

B. Fielal, MChOrth, FRCS, FRCSEd, Consultant Orthopaedic Surgeon

The London Hospital, Whitechapel, London El IBB, England.

M. Greiss, MCh Orth, FRCS, Registrar

Robert Jones \& Agnes Hunt Orthopaedic Hospital, Oswestry, Shropshire SY10 7AG, England.

Requests for reprints should be sent to Mr B. Helal.

(C) 1984 British Editorial Society of Bone and Joint Surgery $0301-620 \mathrm{X} / 84 / 2032 \$ 2.00$
The purpose of this present review is to assess the long-term results and to report useful modifications in technique and management.

\section{ASSESSMENT}

Clinical examination must include an inspection of the patient walking, of the state of the plantar skin and of the mobility of the joints of the foot. Martorell (1973) has drawn attention to the mobility of the metatarsal heads and has devised an apparatus to assess their mobility quantitatively. Mobility depends on the state of the tarsometatarsal joint and upon adherence to the soft tissues around the metatarsal heads. In examining a patient with pressure metatarsalgia, the metatarsal heads are pushed dorsally to see whether they are mobile. If the mobility is normal then one should examine the hindfoot for a fixed pronation or supination deformity which can produce abnormally high pressures on the forefoot. Special investigations to assess pressure distribution in the foot are useful so that accurate comparisons can be made with the situation after treatment. We have used the Harris and Beath (1947) pad-technique (Figs 1 and 2) and a pedobarograph apparatus.

Anteroposterior and lateral radiographs are taken with the patient bearing weight. Three radiographic changes are of importance in the context of pressure metatarsalgia. First, the length of the metatarsals in relation to each other. Viladot in 1962 drew attention to three types of foot based upon the relative lengths of the toes: a square pattern in which the first to the fourth toes are equal in length; the Egyptian type in which the great toe is the longest and the rays reduce in length progressively from the second to the fifth toe; and the Greek type in which the second toe is the longest followed by the third, first, fourth and fifth. The Greek foot with its relatively short first metatarsal is prone to develop pressure metatarsalgia. Secondly, the relation of the sesamoids of the great toe to the first metatarsal head. Lateral displacement of the sesamoids occurs in gross 

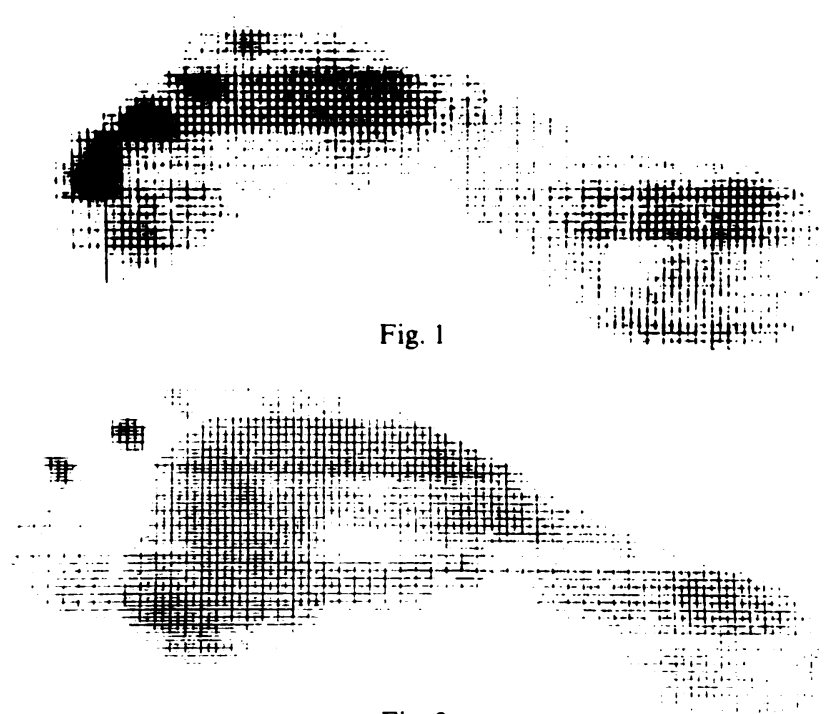

Fig. 2

Figure 1-Pressure recordings of the foot before osteotomy of the middle three metatarsals. Figure 2-After osteotomy; high points of pressure have disappeared and the toe pads have reappeared.

hallux valgus. Proximal displacement of the sesamoids frequently occurs after the Keller operation which, by removing the base of the proximal phalanx of the great toe, often detaches their distal insertion allowing them to migrate proximally. As the sesamoids lie beneath the first metatarsal head they normally raise it; if they are displaced the metatarsal head drops plantarward and this results in a shift of pressure to the lesser metatarsals. Similar findings after the Keller operation were reported by Henry and Waugh (1975). Thirdly, absence of a metatarsal head due to a previous operation or abnormalities of shape as after Freiberg's disease. A smaller head results in the others taking excess pressure and a larger head results in a high pressure point beneath it.

Osteotomy is indicated in the presence of painful callosities under metatarsal heads which do not move dorsally when pressure is applied to their plantar surface.

\section{SURGICAL TECHNIQUE}

The operation is performed under a general anaesthetic and a tourniquet is used. A longitudinal dorsal incision about $3 \mathrm{~cm}$ in length is made over the central metatarsal, starting distally over the metatarsal head. With pointed scissors the second metatarsal neck is sought and the distal third of its shaft exposed. Spike retractors are inserted and with a narrow-gauge oscillating saw the metatarsal is divided, starting proximally on the dorsum and proceeding distally and plantarward at an angle of $45^{\circ}$. Any excessive dorsal spike is trimmed off with a bone nibbler. It is most important to slide an osteotome between the bone and the plantar soft-tissue to free the head which will then displace dorsally and proximally (Fig. 3). The third and fourth metatarsals are dealt with similarly. The subcutaneous tissues and skin are sutured.
No plaster is used and early weight-bearing is encouraged.

Fixed claw-toes are manipulated by rupturing the volar capsular structures of the interphalangeal joints. If the joints do not remain straight the flexor apparatus is tenotomised distally. Generally, however, the telescoping osteotomy relaxes the flexor tendon and the claw toe straightens satisfactorily.

A felt pad is placed under the middle metatarsal heads and a thick wool and crepe dressing is applied. The foot is kept elevated for $\mathbf{4 8}$ hours and the patient is then encouraged to take short walks taking as much pressure on the forefoot as discomfort will allow. This activity is gradually increased and the patient is usually discharged on the fifth day. The wool padding is retained for two weeks and the patient then wears loose fitting sandals or shoes. The osteotomy is usually stable in three to four weeks and unrestricted walking can be allowed.

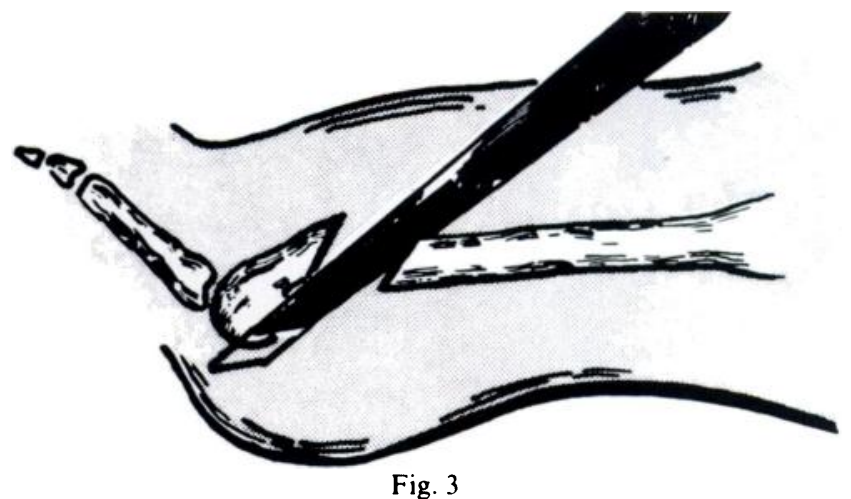

Freeing the metatarsal head from its plantar aspect is an important manoeuvre since the head is often incarcerated in the underlying soft tissues.

If osteotomies of the first and fifth metatarsals are needed these should ideally be carried out at a different time; this is because they require postoperative plaster, which would prevent the early weight-bearing needed after osteotomies of the middle three metatarsals.

Osteotomies of the first and fifth metatarsals are angled obliquely so that each head slides proximally and towards the adjacent metatarsal. For osteotomy of the great toe a second obliquity is given to the cut so that the proximal portion overrides the distal; this prevents unwanted dorsal displacement of the head. If it is essential to carry out osteotomies on the first and fifth metatarsals at the same time as the middle metatarsals, then the foot has to be placed in a carefully moulded plaster cast. Dislocations of the metatarsophalangeal joints can be ignored for they are generally not a source of pain (Figs 4 and 5).

The importance of early weight-bearing. Many authors have stressed that secure internal fixation of the osteotomy is essential to prevent non-union and to prevent the danger of over or under correction. Various methods to achieve fixation have been devised, such as plating, stainless steel wiring, and stapling (Duyck 1977). We believe that fixation is not only unnecessary, it is actually 


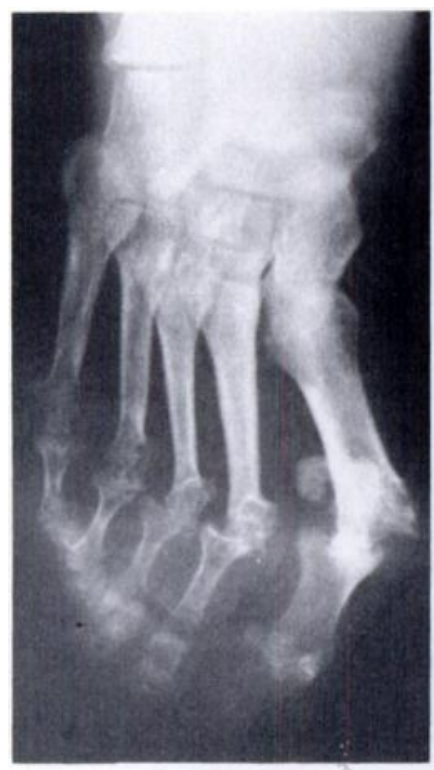

Fig. 4

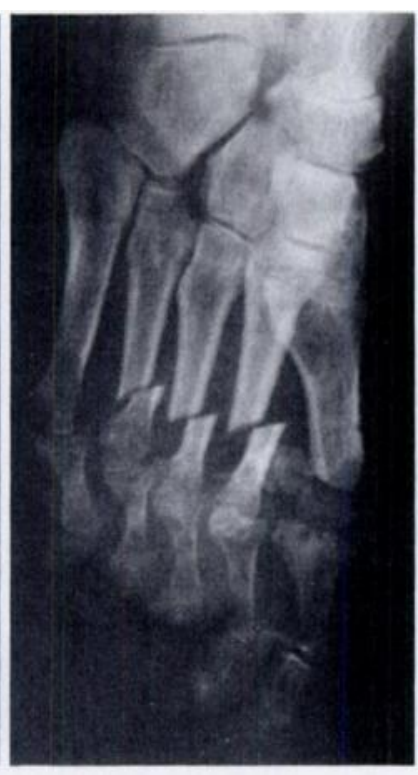

Fig. 5
Figure 4-The dislocations of the metatarsophalangeal joints were ignored in this rheumatoid foot. Figure 5-Osteotomies of the second. third and fourth metatarsals and the replacement of the first metatarsophalangeal joint by a new joint resulted in a symptomless foot.

harmful. Levelling of the metatarsal heads so that there is an even distribution of pressure across them will automatically be achieved by early weight-bearing on the heads. The necessary degree of correction is obtained by the mere act of walking.

\section{REVIEW}

The observations described are based on a retrospective study of 508 feet in 310 patients reviewed at the London Hospital, the Enfield District Hospital and the Derbyshire Royal Infirmary. Two hundred and seventy-four patients $(88.4 \%)$ responded to requests for reattendance; $8(2.6 \%)$ had died and $28(9.0 \%)$ had moved home. All patients had suffered pressure metatarsalgia of varying degree and severity, and involving varying metatarsal heads. All 310 patients had telescoping osteotomies between October 1967 and July 1979; 64\% had bilateral procedures.

At review the mean age of the patients was 55 years; range 19 to 88 years. There were 68 men (21.9\%) and 242 women $(78.1 \%)$. The majority were women aged between 40 and 60 years. In 69 patients ( 65 women and 4 men) the metatarsalgia was the result of rheumatoid arthritis.

The length of follow-up ranged from 1 to 12 years with a mean of 4.3 years; $47 \%$ of the patients had a follow-up of more than 5 years.

The following criteria were used in evaluating the post-operative results.

Clinical assessment. Pain. The patients were asked whether they had pain under the metatarsal heads that had previously been painful, and also under those that had previously been painless.
Callosities. The state of previous callosities was inspected and a search carried out for new callosities under previously unaffected metatarsal heads.

Footwear. The patients were asked whether they could wear standard shoes of their own choice.

Chiropody. The patients were asked whether they were having chiropody.

Oedema. The presence or absence of residual swelling of the foot or the forefoot was noted.

Radiographic assessment. All patients had anteroposterior and lateral radiographs taken six weeks after operation; these were repeated at the long-term review in 1982. The position of the osteotomy, the state of union and the alignment of the metatarsal heads relative to one another were noted.

\section{RESULTS}

Clinical results. Pain. At the final review $274(88.4 \%)$ of the patients had no pain at all and had resumed their normal range of activities.

The remaining 36 patients $(11.6 \%)$ had pain. Twenty-one patients had pain at the site of previously operated metatarsals; 4 of these had painful non-unions, and in 17 the pain was due to a recurrence of callosities because of inadequate displacement of metatarsal heads (this was mainly due to failure to free the heads from their incarceration in soft tissue). The remaining 15 patients had pain under unoperated metatarsals: 8 had pain under one of the middle metatarsals adjacent to an operated one; and 7 , in whom all three middle metatarsals had been osteotomised, had pain under the fifth metatarsal.

Callosities. At review $467(92 \%)$ of the feet were totally devoid of any plantar callosities, although all had had callosities before operation (Figs 6 and 7).

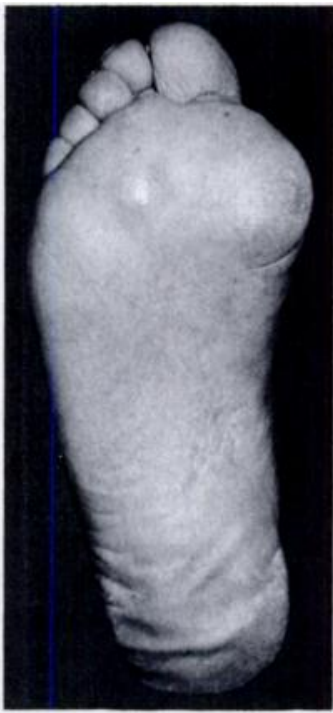

Fig. 6

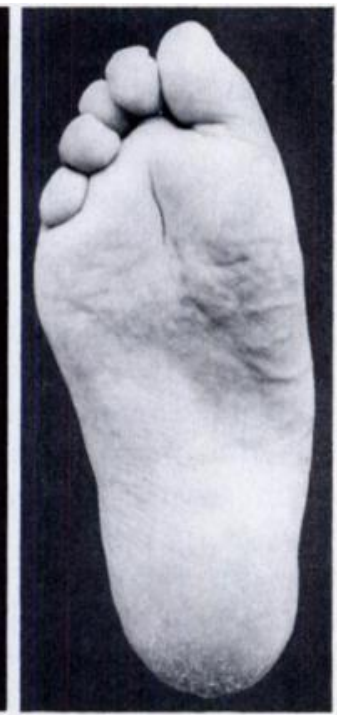

Fig. 7
Figure 6-Before operation the patient had a prolapsed arch and painful callosities. Figure 7-After operation the callosities disappeared and the prolapse was corrected. 


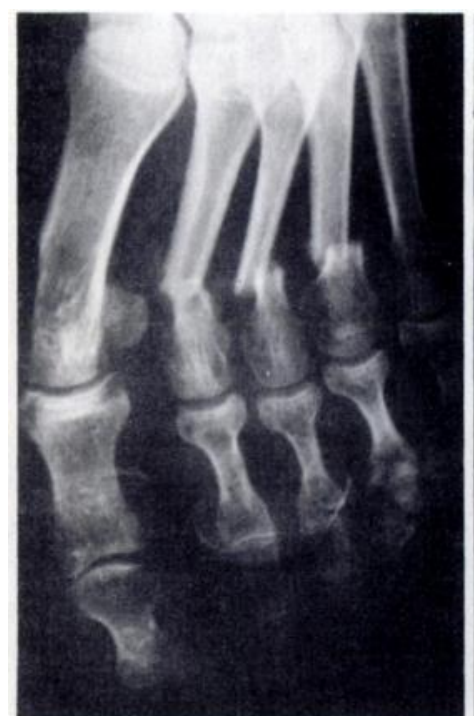

Fig. 8

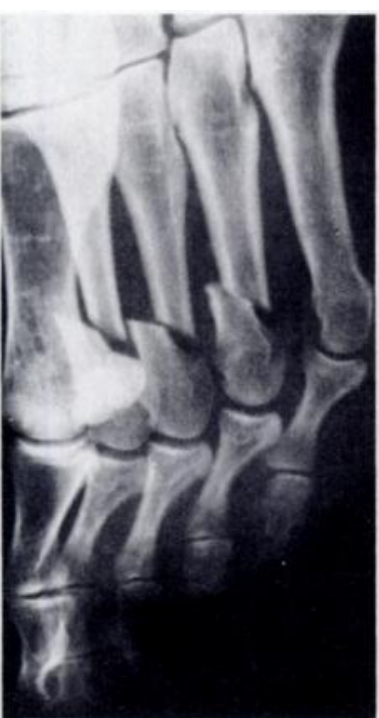

Fig. 9

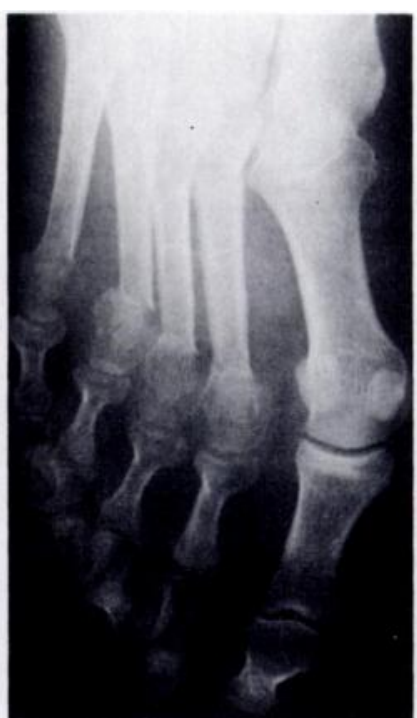

Fig. 10

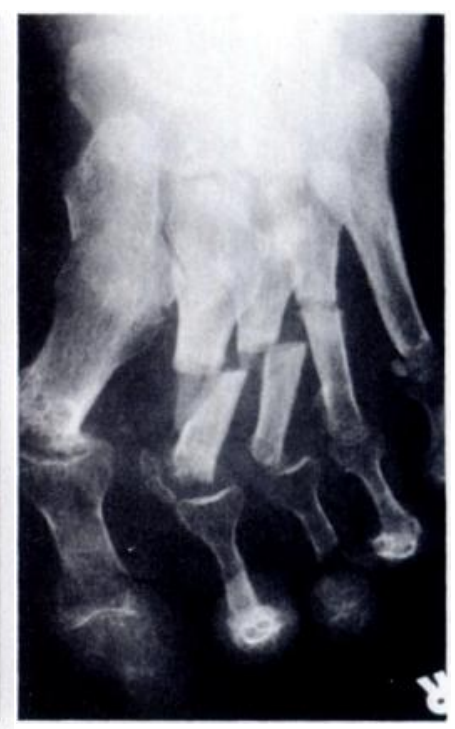

Fig. 11

Figures 8 and 9-Anteroposterior and oblique radiographs showing the optimal position for osteotomy in the distal third of the metatarsal shaft. Figure 10-The most distal acceptable site. Figure 11 -The most proximal acceptable site.

Painless callosities were found in 39 feet and painful ones in two. There were 21 feet in which callosities under the heads of osteotomised metatarsals had not disappeared by the time the patients were reviewed, but these feet were painless. There appeared to be a direct relationship between the time which had elapsed since operation and the disappearance of callosities, since only two of the feet with residual callosities had been operated upon more than two years before review. This contradicts other reports where disappearance of callosities is claimed to occur much earlier (Duyck 1977).

In 14 feet, new but so far painless callosities had developed, mostly under the fifth metatarsal heads, less commonly under the first. Two feet developed painful callosities under the fifth metatarsal heads necessitating osteotomies.

Of the feet with variable degrees of pre-operative clawing of the toes, 26 had reported painful dorsal callosities on the toes before operation. These had disappeared in 22 after the operation, and although they were still present in 4 they were asymptomatic at the time of review.

Footwear. One hundred and thirty-six patients (44\%) could wear any type or shape of footwear they wanted after operation; before operation only $9(2.9 \%)$ had an unrestricted choice. Seventy-seven $(24.8 \%)$ complained that, as a result of their feet having become wider and somewhat shorter, they experienced difficulty in finding a suitable size of footwear; for most activities, including walking, this group was limited to soft, pliable, flat shoes. The remaining patients said they could only find comfort in low heeled shoes, but otherwise were unrestricted as to shape and type of shoe. Just over half the patients were found to have some problems with footwear after lesser metatarsal osteotomies, compared with $97.1 \%$ preoperatively.
Chiropody. None of the patients who had been to chiropodists at some stage before operation had treatment after operation. However, patients with new postoperative callosities under metatarsal heads adjacent to those that had been operated on were having regular chiropody. Oedema. Forty-eight patients complained of a degree of residual swelling of the operated foot, or feet, especially after prolonged walking; they all had undergone operation less than 18 months before review.

Radiographic results (Figs 8 to 11 ). In 27 patients (8.7\%) the position of the osteotomy was incorrect. The metatarsal heads had failed to displace dorsally and proximally in 7 osteotomies, 4 osteotomies had been too vertical which had prevented adequate overriding, and 3 had been too distal producing bony spikes and malunion. A sharp bony spike on the dorsal aspect caused symptoms in one patient.

Forty-eight patients $(15.5 \%)$ had radiographic evidence of non-union of one or more osteotomies; in 37 the

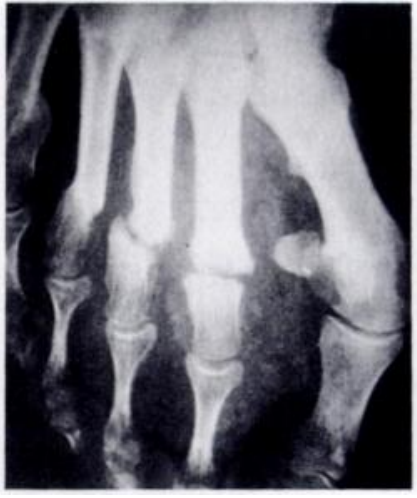

Fig. 12

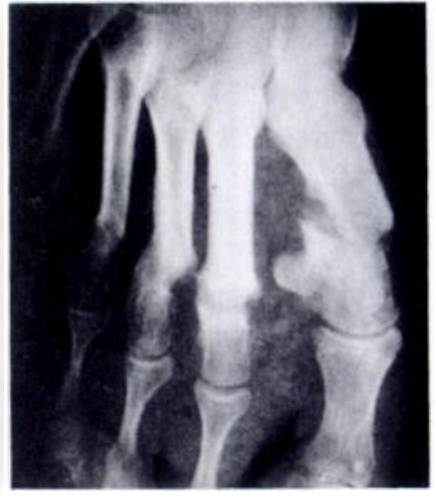

Fig. 13
Figure 12-Radiograph showing non-union after osteotomy of the second and third metatarsals. Figure 13-Osteotomy of the first metatarsal and a period in plaster has resulted in union of previously ununited metatarsals. 
non-unions gave rise to neither symptoms nor clinical signs. This differs from the findings of Duyck (1977), who reported a rate of non-union of $17.1 \%$, half of which were symptomatic; however, internal fixation was used in his series.

Table I. Scoring system

\begin{tabular}{|lc|}
\hline & Score \\
\hline Pain & 10 \\
None & 5 \\
Moderate & 0 \\
Severe & \\
Footwear & 10 \\
Normal & 5 \\
Insoles & 0 \\
Special shoes & \\
Locomotion & 10 \\
Able to run & 5 \\
Walking unrestricted & 0 \\
Walking restricted & \\
\hline
\end{tabular}

Postoperative complications. These included haematoma formation $(7 \%)$, wound dehiscence $(12 \%)$, superficial sepsis $(4 \%)$, symptomatic non-union $(1.2 \%)$, and malalignment $(4 \%)$ (malalignment was generally due to a technical error and was corrected by a second osteotomy).

Non-union was ignored unless painful; those that were painful were treated by either a period in plaster, osteotomy of an adjacent intact metatarsal, or division of intermetatarsal ligaments to allow better telescoping and bone contact (Figs 12 and 13).

The results were assessed using a scoring system which was based on symptoms, type of footwear worn and the ability to walk and run (Table I). Patients with a
Table II. Summary of results

\begin{tabular}{|lll|}
\hline & \multicolumn{2}{l|}{ All patients (percentage) } \\
\cline { 2 - 3 } Results & $\begin{array}{l}\text { After initial } \\
\text { osteotomy }\end{array}$ & *After re-operation \\
\hline Good & 77 & 88 \\
Moderate & 14 & 8 \\
Poor & 9 & 4 \\
\hline
\end{tabular}

* 37 patients $(12 \%)$ had a repeat osteotomy

score of 20 to 30 were classed as having a good result, those with 15 to 20 a moderate result and those with less than 15 a poor result. A summary of the results is shown in Table II. It should be noted, however, that of the patients with rheumatoid arthritis $71 \%$ had a good result, $19 \%$ a moderate result, and $10 \%$ a poor result; $4 \%$ of those with a poor result (4 patients) had excision arthroplasty as a salvage procedure.

The figures for the last two years of the trial reflect a marked improvement in the results. This is due to (1) better preoperative investigation and selection, and the recognition of hindfoot abnormalities which contribute to forefoot pressure; (2) better atraumatic technique and accuracy in placing the osteotomy; (3) better displacement by freeing the head from the plantar soft tissues; and (4) always performing the middle three metatarsal osteotomies together and dividing the first and fourth space intermetatarsal ligaments when necessary to secure adequate displacement.

\section{CONCLUSION}

Given the correct indications, the procedure described is a valuable one for the management of pressure metatarsalgia. Rheumatoid patients respond as well as other patients and their convalescence is more rapid than can be achieved by the alternative procedure, which is excision of the metatarsal heads.

We are grateful to Mr A. P. J. Henry, Consultant Orthopaedic Surgeon, Derbyshire Royal Infirmary, for allowing us to include his patients in this review. We wish to thank Mrs Jenny Parke for the typescript and Miss Pat Burgess of the Department of Photography, the London Hospital, for the photographs.

\section{REFERENCES}

DuVries HL. Surgery of the foot. 2nd ed. St Louis: CV Mosby Co, 1965:204.

Duyck JP. Des osteotomies metatarsiennes dans le traitement des troubles statiques de l'avant-pied. Thesis, University of Marseille, 1977.

Harris RL, Beath T. Army foot survey : an investigation of foot ailments in Canadian soldiers. Ottawa: National Research Council of Canada 1947; NRC no. 1574 .

Helal B. Metatarsal osteotomy for metatarsalgia. J Bone Joint Surg [Br] 1975;57-B:187-92.

Henry APJ, Waugh W. The use of footprints in assessing the results of operations for hallux valgus: a comparison of Keller's operation and arthrodesis. J Bone Joint Surg [Br] 1975;57-B:478-81.

Kelikian H. Hallux valgus, allied deformities of the forefoot and metatarsalgia. Philadelphia, London: WB Saunders, 1965.

Martorell J. Concepts et études sur la metatarsalgie et son traitement. Podologie 1973;8:237-70.

Viladot A. Fisiopatologia del antepie. Podologie 1962;1:87-99. 